\title{
Evaluation of physicochemical and microbiological stability of liquid preparation from tizanidine hydrochloride tablets - a Hospital concern
}

\author{
Caren Gobetti $^{\circledR 1^{*}}$, Andressa da Silva Bitencourt ${ }^{2}$, Márcio Vinícius Ayres ${ }^{1}$, \\ Ana Lucia Peixoto de Freitas ${ }^{2}$, Andreas Sebastian Loureiro Mendez ${ }^{1,2}$, \\ Cássia Virginia Garcia ${ }^{1,2}$
}

\author{
${ }^{1}$ Programa de Pós-Graduação em Ciências Farmacêuticas, Faculdade de Farmácia, \\ Universidade Federal do Rio Grande do Sul, Porto Alegre, RS, Brasil, ${ }^{2}$ Faculdade de \\ Farmácia, Universidade Federal do Rio Grande do Sul, Porto Alegre, RS, Brasil
}

\begin{abstract}
Tizanidine hydrochloride is a centrally acting skeletal muscle relaxant, used in the management of spasticity. This drug is commercially available only as tablets, which highlights the need to develop oral liquid formulations. In the hospital environment, this aspect is circumvented by the preparation of suspensions, to allow administration to children and adults with impaired swallowing, but there are no data regarding their stability. The purpose of this study was to evaluate the physicochemical andmicrobiological stability of liquid dosage forms prepared in the hospital environment from tizanidine hydrochloride tablets, applying high performance liquid chromatography (HPLC) and microbiological analysis. A simple and stability-indicating HPLC method was developed and validated for specificity, linearity, limits of detection and quantification, precision, accuracy and robustness. The liquid formulations were placed in amber PET and glass bottles, which were stored under three different conditions: at room temperature, under refrigeration and at $40{ }^{\circ} \mathrm{C}$. The liquid formulations were analyzed and demonstrated chemical stability for 56 days, allowing their use for long periods. However, the determination of microbiological stability showed that these formulations are prone to microbial contamination, which has dramatically reduced its stability to 7 days, in both bottles and at all evaluated temperatures.
\end{abstract}

Keywords: Tizanidine hydrochloride. Liquid preparation. Physicochemical and microbiological stability. High-performance liquid chromatography.

\section{INTRODUCTION}

Tizanidine hydrochloride 5-chloro-4-(2-imidazolin2-yl-amino)-2,1,3-benzothiadiazole hydrochloride is a centrally acting skeletal muscle relaxant. It is a central alpha-2 adrenoceptor agonist and myotonolytic agent used to treat spasticity in patients with cerebral or spinal injury. It is an antispastic agent with similar efficacy to that of baclofen and a more favorable tolerability profile (Qi, Wang, Wang, 2002; Sweetman, 2011). While drowsiness

*Correspondence: C. Gobetti. Universidade Federal do Rio Grande do Sul (UFRGS). Mailing address: Av. Ipiranga 2752, 90610-000, Porto Alegre/ RS, Brasil. Telephone: (51) 3308-5214. E-mail: carengobetti@hotmail.com is a frequently reported adverse effect with both agents, subjective muscle weakness appears to be less of a problem with tizanidine hydrochloride, and therefore it appears to be an attractive therapeutic alternative for patients (Wagstaff, Bryson, 1997).

A study demonstrated that tizanidine hydrochloride is an effective and safe drug to decrease spasticity in children with cerebral palsy, and concluded on the basis of experimental findings that it could be considered as a useful anti-spastic drug for the treatment of spastic cerebral palsy in childhood. Unfortunately few, limited studies have been conducted on the effect of tizanidine hydrocloride in children. Despite these limited evaluations, many neurologists recommend its use to treat spasticity 
in childhood (Nikkhah et al., 2011). The effect of this drug on 45 children with spasticity in cerebral palsy was reported in a study, showing that tolerance was excellent in $79.3 \%$ of children and subjective assessment by $92.9 \%$ of parents was good (Palazon, Benavente, Arroyo, 2008).

As indicated above, this is a drug that apparently meets the clinical needs of children, although it does not present dosage forms available for pediatric use, as solutions and suspensions, since it is commercially available only in tablet dosage forms. Due to the lack of pharmaceutical forms suitable for pediatrics, hospitals use dissolved crushed tablets as an alternative. Accordingly, such preparations are administered without any information on their bioavailability, efficacy and toxicity. There is also a lack of information on their compatibility and stability, as well as risks of dose inaccuracy, contamination and interactions (Guzmán et al., 2012; Rosa et al., 2014).

The diversity of the pediatric population leads pharmacists to face several challenges mainly related to the acquisition, provision and use of drugs in this group of patients. Calculation of the pediatric dose is of particular concern to pharmacists. Another challenge is the unavailability of formulations suitable for pediatric use, leading many pharmacists to prepare extemporaneous liquid preparations, even though data on the stability of such preparations are scarce (Balan, Hassali, Mak, 2017).

Studies have shown that between $24.1 \%$ and $31.0 \%$ of all tablets prescribed for adult patients in primary care are split prior to administration. Guidelines advise that modifications should only be undertaken as a "last resort" when "other methods have been considered". However, despite this, evidence shows that oral dosage form modifications are a routine part of clinical practice. A systematic review has highlighted the key factors influencing the knowledge, attitudes and beliefs of patients and healthcare professionals about oral dosage form modifications. The findings suggest that the patients' needs should be routinely assessed but reliable and pertinent information from drug manufacturers, guidelines and recommendations from healthcare colleagues are needed to support this (Gillicuddy et al., 2017).

An oral liquid preparation would be advantageous for patients such as children or adults with impaired swallowing or using enteral feeding tubes (Santos, Heineck, 2011). In hospital routine, derivations (alterations from the solid dosage form to non-sterile liquid form, usually oral suspensions) are prepared following the criterion of an existing stability study in the literature. Some works are available discussing the stability of extemporaneous suspensions prepared from tablets, such as the case of physical, chemical and microbiological stability of compounded carbimazole suspension and minoxidil suspension (Lwin et al., 2016a; Lwin et al., 2016b).

To date, there is a lack of data in the literature involving the behavior of tizanidine hydrochloride after derivation. Thus, in this study, the liquid preparation formulated from $2 \mathrm{mg}$ tizanidine hydrochloride tablets by the pharmacy service of a University Hospital was evaluated concerning the physicochemical and microbiological stability of these formulations, in order to overcome the day-to-day challenges of life in hospitals and to ensure that children have a high level of safety in the use of medicines. The validation of the analytical method was performed to certify the accuracy of the results.

\section{MATERIAL AND METHODS}

\section{Chemicals}

Tizanidine hydrochloride reference substance (99.8\%) was adquired from The United States Pharmacopeia and Sirdalud ${ }^{\circledR} 2 \mathrm{mg}$ tablets bath number 1601363 and expiration date 12/2017 (Novartis, São Paulo, Brazil) were obtained in the local market.

Methanol high performance liquid chromatography (HPLC) grade (Vetec $\AA$, Rio de Janeiro, Brazil), purified water (Millipore ${ }^{\circledR}$ Direct-Q3UV, Molsheim, France), triethylamine analytical grade $($ Tedia $\AA$, Fairfield, United States) and orto-phosphoric acid 85\% (Vetec $\AA$, Rio de Janeiro, Brazil) were used for sample preparation and mobile phase composition. Sabouraud dextrose agar (Himedia ${ }^{\circledR}$, Mumbai, India), soybean-casein digest agar (Himedia ${ }^{\circledR}$, Mumbai, India), and Macconkey agar (Kasvi ${ }^{\circledR}$, Italy) were the mediums used for microbiological testing.

\section{Instrumentation and analytical conditions}

An HPLC system (Shimadzu 20A, Kyoto, Japan) with a LC-20AT pump, SIL-20AC auto sampler, CTO-20AC column oven and SPD-M20A diode array detector set at $227 \mathrm{~nm}$ was used for method development, validation and physicochemical stability. Data acquisition and analysis were done by LC Solution software.

Chromatographic conditions were defined by the authors. Chromatographic analysis was performed in a Phenyl Zorbax Eclipse XBD Agilent ${ }^{\circledR}$ column $(250 \mathrm{~mm}$ $\mathrm{x} 4.6 \mathrm{~mm}, 5.0 \mu \mathrm{m})$ maintained at $25^{\circ} \mathrm{C}$. The mobile phase 
was composed of methanol and water $(50: 50 \mathrm{v} / \mathrm{v})$ with $0.5 \%$ trimethylamine adjusted to $\mathrm{pH} 3.5$ with phosphoric acid in an isocratic mode at a flow rate of $0.6 \mathrm{~mL} / \mathrm{min}$ and the sample solution injection volume was $20 \mu \mathrm{L}$.

\section{Standard and Sample Preparation}

The stock solution of tizanidine hydrochloride reference standard $(200.0 \mu \mathrm{g} / \mathrm{mL})$ was prepared in water since the drug is soluble in this solvent. The working standard solution $(30.0 \mu \mathrm{g} / \mathrm{mL})$ was obtained by dissolution in the same solvent.

For sample preparation, twenty tablets were weighed and crushed to a fine powder. A quantity of the powdered tablets equivalent to $20.0 \mathrm{mg}$ of tizanidine hydrochloride was transferred to a $100 \mathrm{~mL}$ volumetric flask. Then, water was added followed by 2 minutes in an ultrasonic bath and the volume was completed until the solution reached 200.0 $\mu \mathrm{g} / \mathrm{mL}$. This solution was filtered using paper and an aliquot of $3.0 \mathrm{~mL}$ from the filtrate was diluted with water until the final concentration of $30.0 \mu \mathrm{g} / \mathrm{mL}$. The solutions were filtered through a $0.45 \mu \mathrm{m}$ membrane filter before injection.

\section{Validation of HPLC method}

The method was validated for specificity, linearity, detection and quantification limits, precision (repeatability and intermediate precision), accuracy and robustness (ICH, 2005). For specificity evaluation, a placebo solution (lactose $62.5 \%$, stearic acid $2.0 \%$, colloidal silicon dioxide $0.5 \%$ and microcrystalline cellulose $35.0 \%$ ) was analyzed, and forced degradation studies were also performed in order to investigate an possible interference. The stress conditions used were: acid and alkaline hydrolysis, radiation, heating and oxidation media. The peak purity was determined using the software tool to confirm the absence of any intervention in the drug peak.

- Effect of acid and alkaline hydrolysis: $10.0 \mathrm{~mL}$ of tizanidine hydrochloride $200 \mu \mathrm{g} / \mathrm{mL}$ were transferred to a $20 \mathrm{~mL}$ volumetric flask and the volume was completed using $\mathrm{HCl} 0,1 M$ or $\mathrm{NaOH} 0,1 M$. After 72 hours, an aliquot of $6.0 \mathrm{~mL}$ the solution was transferred to a 20 $\mathrm{mL}$ volumetric flask, neutralized by $\mathrm{NaOH} 0.1 M$ (acid hydrolysis) or with $\mathrm{HCl} 0.1 M$ (alkaline hydrolysis) and diluted with water until the final concentration $30 \mu \mathrm{g} / \mathrm{mL}$.

- Effect of UV-A and UV-C radiation: aliquots of $2.0 \mathrm{~mL}$ of tizanidine hydrochloride $200 \mu \mathrm{g} / \mathrm{mL}$ were placed in closed plastic cells $(1 \mathrm{~cm})$, which were exposed to UV-A light $(352 \mathrm{~nm})$ or UV-C light $(254 \mathrm{~nm})$ for 72 hours in mirror chambers $(100 \times 18 \times 17 \mathrm{~cm})$. After exposure to radiation, a $3.0 \mathrm{~mL}$ aliquot was transferred to a $20 \mathrm{~mL}$ volumetric flask and the samples were diluted to $30 \mu \mathrm{g} /$ $\mathrm{mL}$ with water. Control samples (wrapped in aluminum foil) were also tested without radiation to evaluate an effect of chamber temperature.

- Effect of oxidation: $10.0 \mathrm{~mL}$ of tizanidine hydrochloride $200 \mu \mathrm{g} / \mathrm{mL}$ were transferred to $20 \mathrm{~mL}$ volumetric flask and the volume was completed using hydrogen peroxide solution (3\%). After 72 hours, an aliquot of $6.0 \mathrm{~mL}$ of the solution was transferred to a $20 \mathrm{~mL}$ volumetric flask and the solution was diluted with water until the final concentration of $30 \mu \mathrm{g} / \mathrm{mL}$.

- Effect of heat: $10.0 \mathrm{~mL}$ of tizanidine hydrochloride 200 $\mu \mathrm{g} / \mathrm{mL}$ were kept in a glass flask at $60^{\circ} \mathrm{C}$ for 72 hours. After this time, a $3.0 \mathrm{~mL}$ aliquot was transferred to a 20 $\mathrm{mL}$ volumetric flask and the samples were diluted to 30 $\mu \mathrm{g} / \mathrm{mL}$ with water to study the effect of heat.

Linearity was determined by three standard curves constructed on three different days in the range of 15.0 to $45.0 \mu \mathrm{g} / \mathrm{mL}$. The curves were statistically evaluated by ANOVA. The quantification limit (LOQ) and the detection limit (LOD) were obtained based on a signal-to-noise approach and the ratio applied was 10:1 for the LOQ and 3:1 for the LOD. The precision of the assay was determined by assaying six samples at $30.0 \mu \mathrm{g} / \mathrm{mL}$ by repeatability (same day) and intermediate precision (three different days). The accuracy was determined by the recovery of known amounts of tizanidine hydrochloride reference standard (corresponding to 5.0, 10.0 and $15.0 \mu \mathrm{g} / \mathrm{mL}$ ) added to the samples of the $30.0 \mu \mathrm{g} / \mathrm{mL}$. The results were expressed as the percentage recovered from the sample. Robustness was evaluated by small variations in the $\mathrm{pH}$ values of the mobile phase, flow rate, wavelength, ratio of the mobile phase as well as column change.

\section{Tizanidine hydrochloride liquid preparation}

Samples of tizanidine hydrochloride liquid preparation $60 \mu \mathrm{g} / \mathrm{mL}$ were prepared by the pharmacy service in the University Hospital in a vertical laminar flow cabinet, according to authors' instructions. To each bottle (glass or PET), 3 tablets of tizanidine hydrochloride $2 \mathrm{mg}$ were added along with $100 \mathrm{~mL}$ of water for injectables. After this, flasks were closed and shaken by hand until a homogeneous aspect was obtained. The suspended matter was some of the insoluble excipients present in the tablets 
since the drug is soluble in water. The suspensions were prepared and three bottles of each material were stored under different conditions: at room temperature $\left(15-30^{\circ} \mathrm{C}\right)$, under refrigeration $\left(2-8{ }^{\circ} \mathrm{C}\right)$ and in the oven at $40^{\circ} \mathrm{C}$. The same sample preparation procedure was carried out for the study of microbiological stability.

\section{Physicochemical stability study}

The evaluation of physicochemical stability was performed during a period of 56 days. Visual appearance, color, odor, $\mathrm{pH}$, degradation products and drug amount were monitored for all temperatures and bottles. The suspensions were vigorously shaken by hand for 2 minutes and easily dispersed. Then, from each bottle, a $5.0 \mathrm{~mL}$ sample was transferred into a $10 \mathrm{~mL}$ volumetric flask and diluted with water until the final concentration of $30 \mu \mathrm{g} / \mathrm{mL}$. All samples were homogenized and filtered using paper and through a $0.45 \mu \mathrm{m}$ membrane before injection. Samples were collected and assayed in triplicate by the HPLC method after 0, 7, 14, 21, 28, 35, 42, 49 and 56 days using the method developed and validated above. At each sampling time $\mathrm{pH}$ values were determined at room temperature using a pHmeter.

In order to monitor the results obtained during physicochemical stability, tizanidine hydrochloride reference standard was prepared in water at a concentration of $30 \mu \mathrm{g} / \mathrm{mL}$.

According to The United States Pharmacopeia (USP $38,2015)$, the general criteria for acceptable levels of tizanidine hydrochloride in tablets are not less than $90.0 \%$ and not more than $110.0 \%$ of the labelled amount. For this reason, the physicochemical stability of the suspension was defined between this range of initial drug concentration. The same criteria were used for extemporaneous benznidazole oral suspension prepared from tablets, where physical stability was evaluated during 90 days and benznidazole concentration was found to be not less than $90.0 \%$ and not more than $110.0 \%$, which were considered as acceptable levels for stability (García, Manzo, Jimenez-Kairuz, 2015).

\section{Microbiological stability study}

The microorganisms were counted by the surface-spread plate method. During the evaluation of microbiological stability, aliquots were always collected from the same flask of each condition, in order to reproduce the routine and the risk of microbial contamination throughout use.
Microbiological experiments were performed according to the Brazilian Pharmacopoeia (BF 2010) and USP 38, 2015 monograph of non-sterile products. For the suitability of pharmacopoeial methods for nonsterile products, the elimination of any antimicrobial property was demonstrated before the verification of the existence of microbial contamination in the product, ensuring a trustworthy method able to eliminate any interference or inhibition during the recovery of the microorganisms.

The microbiological stability was performed to establish the time of safe use of the liquid preparation, demonstrating the storage period and conditions that maintain the properties and prevent the harmful effects resulting from microbial contamination. Ten $\mathrm{mL}$ of sample of each condition were diluted with $\mathrm{pH} 7.2$ phosphate buffer to obtain 1:10 dilution (S1), and the samples were further diluted in the same solvent to obtain 1:100 (S2) and 1:1000 (S3) dilution. Then, $100 \mu \mathrm{L}$ of each level of dilution were pipetted into each of two sterile Petri dishes containing $20 \mathrm{~mL}$ of soybean-casein digest agar and two sterile Petri dishes containing $20 \mathrm{~mL}$ of sabouraud dextrose agar. For the total aerobic bacterial count, the Petri dishes of soybean-casein digest agar were incubated at $32.5^{\circ} \mathrm{C} \pm 2.5^{\circ} \mathrm{C}$ for 3 days and for the total yeast and mold count the Petri dishes of sabouraud dextrose agar were incubated at $22.5^{\circ} \mathrm{C} \pm 2.5^{\circ} \mathrm{C}$ for 5 days. The plates were examined for growth.

For detection of Escherichia coli, $1 \mathrm{~mL}$ of the solutions S1, S2 and S3 was diluted in soybean-casein digest medium, homogenized and the solutions obtained were named E1, E2 and E3. These samples were incubated at $32.5^{\circ} \mathrm{C} \pm 2.5^{\circ} \mathrm{C}$ during 24 hours. Then, $100 \mu \mathrm{L}$ of the solutions E1, E2 and E3 were added into each of two sterile Petri dishes containing $20 \mathrm{~mL}$ of Macconkey agar. The plates were incubated at $32.5^{\circ} \mathrm{C} \pm 2.5^{\circ} \mathrm{C}$ for 48 hours and then examined for growth.

Samples were collected after 0, 7, 14 and 21 days, the arithmetic mean per culture medium of the counts was used to calculate the number of cfu per $\mathrm{mL}$ of the product. According to the BF 2010 and USP 38, 2015, the acceptance criteria for non-sterile pharmaceutical products in the category of aqueous preparations for oral use based upon the total bacterial and total combined yeasts and mold count is less than $10^{2} \mathrm{cfu} / \mathrm{mL}$ or $10^{1} \mathrm{cfu} /$ $\mathrm{mL}$ of sample, respectively, and Escherichia coli must be absent. All procedures were performed under aseptic conditions and sterilized materials were used to prevent any type of contamination. 


\section{RESULTS E DISCUSSION}

\section{Development and validation of analytical method}

During the optimization of the method different columns $\left(\mathrm{C}_{18}, \mathrm{C}_{8}\right.$ and Phenyl), organic solvents, aqueous phase with or without trimethylamine, different $\mathrm{pH}$ values and flow rate were tested.

In the development method, a $\mathrm{C}_{18}$ column was used because of its more frequent use involving tizanidine hydrochloride in articles and USP 38, 2015 (Dudhe et al., 2013; Kumar et al., 2010; Nalluri et al., 2012; Narajji et al., 2011). Using the $\mathrm{C}_{18}$ column with different proportions of mobile phase containing methanol, water and acetonitrile, a retention time was obtained around 3.0 minutes of analysis, with amplification of the chromatographic signal and number of theoretical plates with an unsatisfactory value. As a second option, the C8 column was used and also did not present satisfactory results, including efficiency and symmetry. Although there is an article involving the use of a Cyano column for the same drug (Qi, Wang, Wang, 2002), our experiments did not detect tizanidine hydrochloride with its use. For this reason a Phenyl column was used and after testing various combinations, the best condition with a retention time of $5.8 \mathrm{~min}$ for tizanidine hydrochloride was obtained using a Phenyl Zorbax Eclipse XBD Agilent ${ }^{\circledR}(250 \mathrm{~mm} \times 4.6$ $\mathrm{mm}, 5.0 \mu \mathrm{m})$ at $25{ }^{\circ} \mathrm{C}$ and mobile phase composed of methanol and water (50:50 v/v) with $0.5 \%$ trimethylamine adjusted to $\mathrm{pH} 3.5$ with orto-phosphoric acid $85 \%$. The method found provided a reproducible retention time and good efficiency.The system suitability parameters were considered satisfactory, with tailing factor 1.19 , number of theoretical plates 11568.72 and retention factor 2.1.

Alterations tested during the development of the method started with the possibility of removing the triethylamine, but the suppression of triethylamine caused an excessive amplification of the chromatographic signal, resulting in an increase of the tailing factor without the addition of the base (1.19 to 2.54 ).

The HPLC method described was specific and the excipients did not interfere in the drug peak (Figure 1). Under UV-C (254 $\mathrm{nm})$ radiation and alkaline hydrolysis, after 72 hours tizanidine hydrochloride content exhibited some decrease and additional peaks were detected. The degradation observed was $25.13 \%$ under UV-C radiation (resolution between the peak at 6.3 minutes and the drug peak was 2.3 ) and $5.53 \%$ after alkaline hydrolysis (resolution between the peak at 5.5 minutes and drug peak was 1.6). When UV-A radiation, acid hydrolysis, oxidation and heating degradation were performed, no degradation was detected and the concentration of the drug remained constant during the exposure time (Figure 2). For the conditions tested, peak purity tool was applied and demonstrated that the drug peak was pure, which showed the specificity of method.

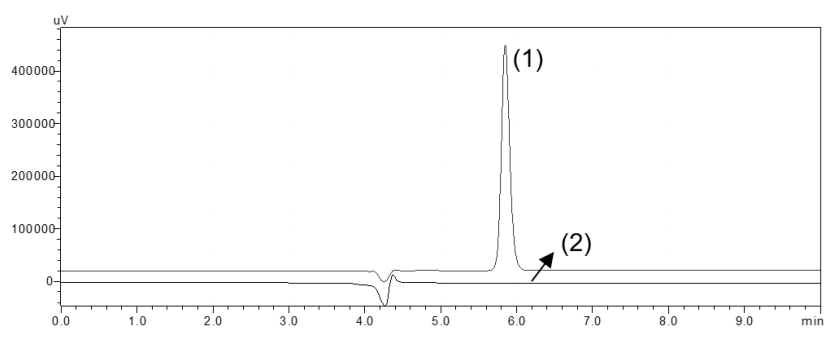

FIGURE 1 - Representative chromatogram of tizanidine hydrochloride sample $30.0 \mu \mathrm{g} / \mathrm{mL}$ (1) and placebo solution (2).
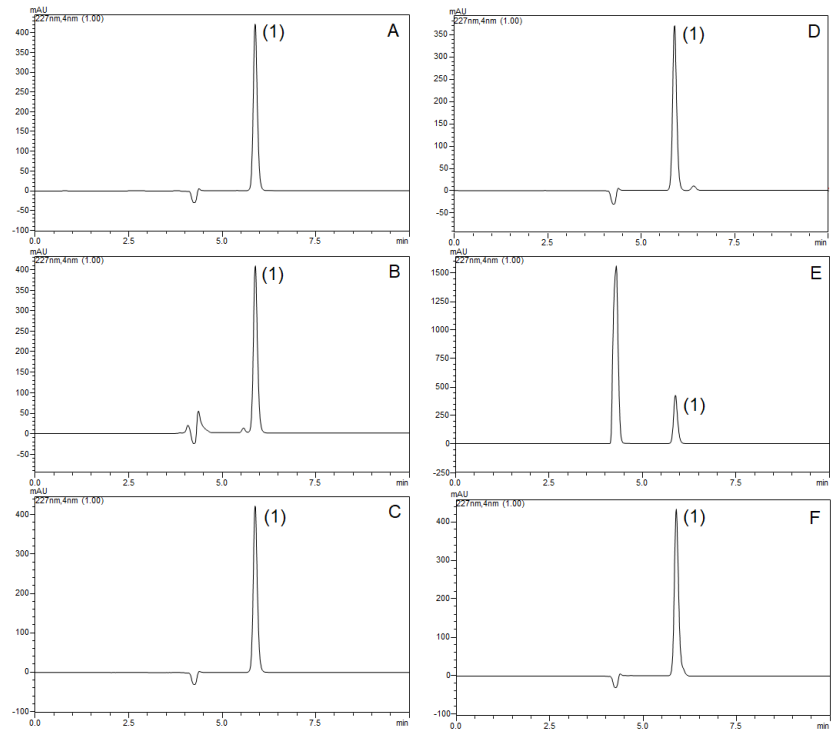

FIGURE 2 - Chromatograms for tizanidine hydrochloride (1) stress tests: acid hydrolysis $(0.1 \mathrm{M} \mathrm{HCl}, 72 \mathrm{~h})(\mathbf{A})$; alkaline hydrolysis (0.1 $M \mathrm{NaOH}, 72 \mathrm{~h})(\mathbf{B})$; UV-A radiation (352 $\mathrm{nm}, 72 \mathrm{~h})(\mathbf{C})$; UV-C radiation $(254 \mathrm{~nm}, 72 \mathrm{~h})(\mathbf{D})$; oxidative degradation $\left(3 \% \mathrm{H}_{2} \mathrm{O}_{2}, 72 \mathrm{~h}\right)(\mathbf{E})$ and heat degradation $\left(60{ }^{\circ} \mathrm{C}\right.$, 72 h) (F).

The method was linear $(r=0.9996)$ at concentrations ranging from 15.0 to $45.0 \mu \mathrm{g} / \mathrm{mL}$. The slope and the intercept obtained from the mean of the three standard curves analysis were 122215 and 2904.3, respectively. According to ANOVA there is linear regression and there is no deviation from linearity $(\mathrm{Fcalc}=0.08<\mathrm{Ftab}=2.96$; 
$\mathrm{p}>0.05)$. The LOD and LOQ were $0.024 \mu \mathrm{g} / \mathrm{mL}$ and $0.09 \mu \mathrm{g} / \mathrm{mL}$ respectively, demonstrating the sensibility of the method. The experimental values obtained for the repeatability demonstrated low values of relative standard deviations (RSD), all below $2.0 \%$ between 0.57 to $1.38 \%$ and the content ranged from $101.74 \%$ (day 1), to $102.13 \%$ (day 2), and $102.81 \%$ (day 3). The intermediate precision demonstrated adequate precision of the analytical method with RDS $1.14 \%$ and content $102.23 \%$. The method accuracy was determined and the mean recovery was found to be $98.49 \%$ (Table I). The method was robust when the influence of $\mathrm{pH}$, flow rate, wavelength, ratio of the mobile phase and column were investigated (Table II).

A stability-indicating HPLC method for the determination of tizanidine hydrochloride was developed and validated based on international guidelines (ICH 2005; USP 38, 2015). The method proved to be simple, sensitive, specific, linear, accurate, precise and robust. Considering its stability-indicating capability, the same was applied to the quantification of a liquid preparation from tizanidine hydrochloride tablets.

TABLE I - Accuracy of HPLC method for determination of tizanidine hydrochloride

\begin{tabular}{cccc}
\hline \multirow{2}{*}{ Samples } & \multicolumn{2}{c}{ Amount of reference substance $(\boldsymbol{\mu g} / \mathbf{m L})$} & Mean Recovery (\%) \\
\cline { 2 - 4 } & Added & Recovery & \\
\hline 1 & 5.0 & 4.91 & 98.18 \\
\hline 2 & 10.0 & 9.84 & 98.39 \\
\hline 3 & 15.0 & 14.83 & 98.89 \\
\hline
\end{tabular}

TABLE II - Robustness of HPLC method for determination of tizanidine hydrochloride

\begin{tabular}{|c|c|c|c|c|}
\hline $\mathrm{pH} 4.0$ & 5.9 & 1.24 & 9561.79 & 100.00 \\
\hline $52 \%$ methanol & 5.6 & 1.20 & 10393.41 & 100.28 \\
\hline $\begin{array}{l}\text { Flow rate } \\
0.5 \mathrm{~mL} / \mathrm{min}\end{array}$ & 7.0 & 1.20 & 12100.00 & 100.20 \\
\hline $\begin{array}{l}\text { Wavelength } \\
225 \mathrm{~nm}\end{array}$ & 5.8 & 1.19 & 10809.02 & 100.31 \\
\hline
\end{tabular}


Evaluation of physicochemical and microbiological stability of liquid preparation from tizanidine hydrochloride tablets - a Hospital concern

TABLE II - Robustness of HPLC method for determination of tizanidine hydrochloride

\begin{tabular}{lccc}
\hline Variable & Retention time (minutes) & $\begin{array}{c}\text { Tailing } \\
\text { factor }\end{array}$ & $\begin{array}{c}\text { Theoretical plates } \\
\text { Amount } \\
(\%)\end{array}$ \\
\hline $\begin{array}{l}\text { Wavelength } \\
229 \mathrm{~nm}\end{array}$ & 5.8 & 1.19 & 10737.47 \\
\hline $\begin{array}{l}\text { Column Phenyl Shim- } \\
\text { pack CLC Shimadzu }\end{array}$ & 6.1 & 1.17 & 13577.63 \\
\hline
\end{tabular}

\section{Physicochemical stability study}

The percentage of initial amount remaining of tizanidine hydrochloride liquid preparation at three controlled temperatures is shown in Table III. The amount value was considered as the mean value of the 3 bottles of each condition. The amount was variable from time zero to 56 days between $1.66 \%$ and $5.07 \%$ for all temperatures and bottles.

TABLE III - The percentage of initial amount of tizanidine hydrochloride remaining, after storage at room temperature $\left(15-30^{\circ} \mathrm{C}\right)$, under refrigeration $\left(2-8^{\circ} \mathrm{C}\right)$ and in oven at $40^{\circ} \mathrm{C}$

\begin{tabular}{|c|c|c|c|c|c|c|c|c|c|c|c|c|}
\hline \multicolumn{5}{|c|}{ Room temperature $\left(15-30^{\circ} \mathrm{C}\right)$} & \multicolumn{4}{|c|}{ Under refrigeration $\left(2-8^{\circ} \mathrm{C}\right)$} & \multicolumn{4}{|c|}{ Oven $\left(40^{\circ} \mathrm{C}\right)$} \\
\hline \multicolumn{5}{|c|}{ Amount (\%) } & \multicolumn{4}{|c|}{ Amount (\%) } & \multicolumn{4}{|c|}{ Amount (\%) } \\
\hline $\begin{array}{l}\text { Time } \\
\text { (days) }\end{array}$ & $\begin{array}{c}\text { PET } \\
\text { bottles* }\end{array}$ & $\begin{array}{l}\text { RSD } \\
(\%)\end{array}$ & $\begin{array}{c}\text { Glass } \\
\text { bottles* }\end{array}$ & $\begin{array}{l}\text { RSD } \\
(\%)\end{array}$ & $\begin{array}{c}\text { PET } \\
\text { bottles* }\end{array}$ & $\begin{array}{r}\text { RSD } \\
(\%)\end{array}$ & $\begin{array}{c}\text { Glass } \\
\text { bottles* }\end{array}$ & $\begin{array}{l}\text { RSD } \\
(\%)\end{array}$ & $\begin{array}{c}\text { PET } \\
\text { bottles* }\end{array}$ & $\begin{array}{l}\text { RSD } \\
(\%)\end{array}$ & $\begin{array}{c}\text { Glass } \\
\text { bottles* }\end{array}$ & $\begin{array}{l}\text { RSD } \\
(\%)\end{array}$ \\
\hline $\mathbf{0}$ & 101.76 & 1.77 & 102.12 & 2.71 & 100.19 & 1.09 & 100.81 & 1.77 & 100.46 & 0.93 & 102.28 & 2.21 \\
\hline 7 & 101.99 & 1.30 & 103.07 & 1.45 & 100.70 & 0.83 & 100.44 & 1.28 & 101.59 & 1.47 & 102.50 & 1.97 \\
\hline 14 & 101.63 & 1.54 & 102.73 & 1.51 & 100.91 & 0.89 & 100.74 & 0.77 & 101.68 & 0.92 & 103.62 & 1.64 \\
\hline 21 & 102.71 & 1.39 & 103.18 & 2.57 & 101.64 & 2.44 & 101.92 & 2.77 & 101.62 & 2.05 & 103.71 & 1.64 \\
\hline 28 & 102.93 & 2.12 & 103.44 & 1.71 & 101.50 & 0.90 & 101.76 & 0.77 & 102.62 & 0.87 & 103.52 & 1.91 \\
\hline 35 & 102.64 & 2.13 & 103.36 & 1.47 & 101.81 & 1.35 & 102.51 & 1.30 & 103.45 & 1.05 & 103.16 & 1.79 \\
\hline 42 & 103.21 & 1.87 & 103.32 & 1.63 & 101.83 & 1.25 & 102.47 & 2.56 & 103.26 & 1.38 & 102.98 & 1.89 \\
\hline 49 & 103.52 & 1.64 & 103.81 & 0.97 & 103.25 & 0.74 & 103.29 & 1.40 & 104.78 & 0.97 & 103.86 & 0.98 \\
\hline 56 & 103.99 & 1.99 & 103.78 & 1.90 & 104.20 & 0.74 & 104.57 & 0.94 & 105.53 & 1.27 & 106.24 & 2.28 \\
\hline
\end{tabular}

*mean of 3 bottles 
In the present experiment, the amount of tizadinine hydrochloride for samples stored at all three temperatures was within values established during evaluation time. None of the conditions presented a reduction of the amount of drug during the period. On the contrary, an increase in the amount was found, which could be related to water evaporation due to poor sealing. The same assumption could also explain the greater variation of the amount of drug observed for $40{ }^{\circ} \mathrm{C}$ PET and glass flasks. Results indicated that temperature and storage flasks showed little influence on the drug amount during 56 days, demonstrating that studied samples were physicochemically stable during the period.

The $\mathrm{pH}$ values of each condition during physicochemical stability were determined and from the results it could be seen that the initial $\mathrm{pH}$ values ranged between 6.16 and 6.46. Although the samples have been subjected to different temperatures and storage bottles, the $\mathrm{pH}$ values presented a slight variation for all samples. At the end of the study, values between 5.91 and 6.32 were found for all samples, indicating that for 8 weeks the $\mathrm{pH}$ presents minimum variations. Although samples were subjected to different conditions, registered $\mathrm{pH}$ values for all samples were close to each other and slightly acid values were generally recommended for oral liquid dosage forms (García, Manzo, JimenezKairuz, 2015). Importantly, the acceptable pH range of solutions for oral administrations is large, ranging from about 5 to $8 \mathrm{pH}$ units (Jones, 2008). Figure 3 shows the $\mathrm{pH}$ profile of each condition during physicochemical stability study.

The physical appearance properties were examined using visual observation of the samples stored under each condition. There were no detectable changes in physical characteristics odor and color, but visible microbiological growth was observed on the $14^{\text {th }}$ day of storage in one sample at room temperature. The appearance remained white (due to the insolubility of the tablet excipients), uniform as on the day of preparation and there were no problems related to flow and resuspension of the preparation in the bottle. Under all conditions evaluated, the purity of the peak was verified with the use of a diode array detector, indicating peak purity of tizanidine hydrochloride at all collection times.
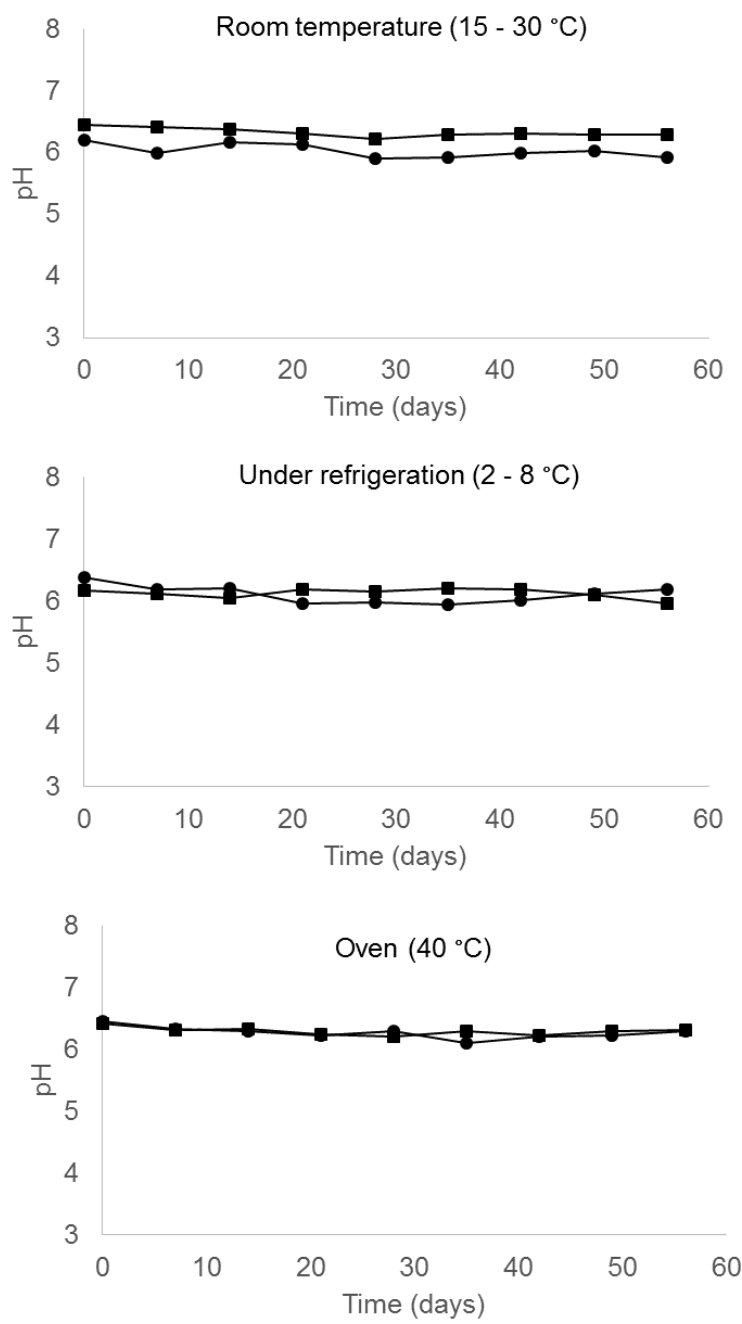

FIGURE 3 - The pH profile of each condition during physicochemical stability study.

\section{Microbiological stability study}

During the study, it was necessary to monitor both physicochemical and microbiological stabilities, combining the amount of drug present during use and acceptable criteria for microorganisms for this type of pharmaceutical form. Oral liquid formulations do not need sterility, but are relevant to use strategies in order to minimize microbial amounts to meet the established limits. Flasks employed were new, cleaned in hospital with alcohol $70 \%$ and dried in an oven, sealed with lids and stored in separate boxes until use.

The total of bacteria, yeast and mold count and detection of Escherichia coli for 21 days are shown in Table IV. At all storage temperatures, it was verified that up to the $7^{\text {th }}$ day no microbial development occurred. On the $14^{\text {th }}$ day of sample collection, $\mathrm{cfu} / \mathrm{mL}$ values were 
above the established acceptance limits (greater than $10^{2} \mathrm{cfu} / \mathrm{mL}$ for aerobic bacteria and greater than $10^{1}$ $\mathrm{cfu} / \mathrm{mL}$ for mold and yeast). These data coincide with the data observed during physicochemical stability, where the presence of turbidity characteristic of fungal contamination was detected in one of the bottles stored at room temperature. Since there had been no bacterial and fungal proliferation in the previous week, sampling was carried out on the $21^{\text {st }}$ day considering the hypothesis that on the $14^{\text {th }}$ day there could be a point of contamination related to the technique or sample collection. However, on the $21^{\text {st }}$ day the data confirmed the values obtained on the $14^{\text {th }}$ day, accounting for above the limits set for these preparations. Colonies characteristic of the presence of Escherichia coli were not found in any of the samples. It should be noted that in the composition of the tablets, probably the lactose is the excipient at the highest concentration. As carbon is one of the most important chemical elements for microbial growth and all organisms require this chemical element in some way (Pelczar, Chan, Krieg, 1997), it is suggested that lactose as a carbon source could act as a source of nutrition and favor the growth of microorganisms. Furthermore, other factors that may favor contamination should be considered, such as a nearly neutral $\mathrm{pH}$, the aqueous vehicle and the absence of antimicrobial preservatives.

TABLE IV - The total of bacteria, yeast and mold count and detection of Escherichia coli for 21 days after storage at room temperature $\left(15-30^{\circ} \mathrm{C}\right)$, under refrigeration $\left(2-8{ }^{\circ} \mathrm{C}\right)$ and in oven at $40^{\circ} \mathrm{C}$

\begin{tabular}{|c|c|c|c|c|c|c|c|c|c|c|}
\hline \multicolumn{5}{|c|}{ Room temperature $\left(15-30^{\circ} \mathrm{C}\right)$} & \multicolumn{3}{|c|}{ Under refrigeration $\left(2-8^{\circ} \mathrm{C}\right)$} & \multicolumn{3}{|c|}{ Oven $\left(40^{\circ} \mathrm{C}\right)$} \\
\hline $\begin{array}{l}\text { Time } \\
\text { (days) }\end{array}$ & Bottle & $\begin{array}{l}\text { Bacteria } \\
\text { (cfu/mL) }\end{array}$ & $\begin{array}{l}\text { Yeast and } \\
\text { mold } \\
\text { (cfu/mL) }\end{array}$ & $\begin{array}{c}\text { Escherichia } \\
\text { coli }\end{array}$ & $\begin{array}{r}\text { Bacteria } \\
\text { (cfu/mL) }\end{array}$ & $\begin{array}{l}\text { Yeast and } \\
\text { mold } \\
\text { (cfu/mL) }\end{array}$ & $\begin{array}{c}\text { Escherichia } \\
\text { coli }\end{array}$ & $\begin{array}{l}\text { Bacteria } \\
(\text { cfu/mL) }\end{array}$ & $\begin{array}{c}\text { Yeast and } \\
\text { mold } \\
(\mathrm{cfu} / \mathrm{mL})\end{array}$ & $\begin{array}{c}\text { Escherichia } \\
\text { coli }\end{array}$ \\
\hline \multirow[t]{2}{*}{$\mathbf{0}$} & PET & $<10$ & $<10$ & absent & $<10$ & $<10$ & absent & $<10$ & $<10$ & absent \\
\hline & Glass & $<10$ & $<10$ & absent & $<10$ & $<10$ & absent & $<10$ & $<10$ & absent \\
\hline \multirow[t]{2}{*}{7} & PET & $<10$ & $<10$ & absent & $<10$ & $<10$ & absent & $<10$ & $<10$ & absent \\
\hline & Glass & $<10$ & $<10$ & absent & $<10$ & $<10$ & absent & $<10$ & $<10$ & absent \\
\hline \multirow[t]{2}{*}{14} & PET & $2.5 \times 10^{3}$ & $7.1 \times 10^{2}$ & absent & $8.4 \times 10^{3}$ & $6.0 \times 10^{2}$ & absent & $2.9 \times 10^{4}$ & $6.8 \times 10^{2}$ & absent \\
\hline & Glass & $8.3 \times 10^{3}$ & $2.6 \times 10^{2}$ & absent & $2.0 \times 10^{3}$ & $9.8 \times 10^{2}$ & absent & $1.0 \times 10^{4}$ & $8.8 \times 10^{2}$ & absent \\
\hline \multirow[t]{2}{*}{21} & PET & $4.7 \times 10^{4}$ & $1.7 \times 10^{3}$ & absent & $1.6 \times 10^{4}$ & $8.6 \times 10^{2}$ & absent & $3.4 \times 10^{5}$ & $2.6 \times 10^{3}$ & absent \\
\hline & Glass & $2.5 \times 10^{4}$ & $2.1 \times 10^{3}$ & absent & $1.5 \times 10^{4}$ & $1.6 \times 10^{3}$ & absent & $3.0 \times 10^{4}$ & $3.6 \times 10^{3}$ & absent \\
\hline
\end{tabular}

Although microbial growth is impaired at low temperatures, it was demonstrated that for both ambient and low temperatures the values of microbial growth were close, which could indicate a contamination due to the applied technique or during sampling. For the $40{ }^{\circ} \mathrm{C}$ samples, values were above other conditions, as expected. Results showed that samples had microbiological stability for 7 days, regardless of temperature or flask type. The lack of microorganisms during this period indicates that safe doses could be administered, since the manipulation is executed in accordance with hospital preparation techniques.

During the interval of sampling times samples were kept at rest, which means that in a period of eight weeks samples were shaken only on sampling days, in a total of eight days. Nevertheless, no visual formation of 
particulates or difficulty of homogenization was observed. One limitation of the study is that the bottles were opened once a week, but the samples may be used for daily administration or even several times a day. In this case, since the bottles are opened more frequently it is unknown how this factor can influence microbiological stability.

Therefore, for safety and because of the variability in the results obtained, a maximum period of use of 7 days has been established, since the liquid formulations are prepared only in water for injectables and do not present preservatives in their composition. As a precaution, storage in PET bottles due to resistance to breakage and refrigerated temperature is suggested to reduce or prevent microbial proliferation.

\section{CONCLUSION}

The proposed HPLC method for the determination of tizanidine hydrochloride was satisfactorily developed and validated, resulting in a simple and fast method, without buffer and with a small amount of organic solvent in the mobile phase.

These liquid preparations of tizanidine hydrochloride may be an alternative to the administration of tablets in hospital, since they demonstrated adequate physicochemical and microbiological stability for 7 days. This indicates that they may be incorporated into the routine for the preparation of the hospital liquid formulations, meeting a demand already indicated, filling the need for the drug and ensuring access with acceptable quality for pediatric patients.

\section{ACKNOWLEDGEMENTS}

This study was financed in part by the Coordenação de Aperfeiçoamento de Pessoal de Nível Superior - Brasil (CAPES) - Finance Code 001.

\section{CONFLICT OF INTEREST}

The authors declare that there are no conflicts of interest regarding this manuscript.

\section{REFERENCES}

Balan S, Hassali MA, Mak VSL. Challenges in pediatric drug use: A pharmacist point of view. Res Social Adm Pharm. 2017;13(3):653-655.
Brazilian Pharmacopoeia. 5 ed. Brasília: Agência Nacional de Vigilância Sanitária; 2010.

Dudhe PB, Jadhav S, Sawarkar V, Nagras MA. Method Development and Validation for Simultaneous Determination of Aceclofenac and Tizanidine in Bulk and Marketed Formulation. Int.J. PharmTech Res. 2013;5(3):1212-1216.

García MC, Manzo RH, Jimenez-Kairuz AF. Extemporaneous benznidazole oral suspension prepared from commercially available tablets for treatment of Chagas disease in paediatric patients. Trop Med Int Health. 2015;20(7):864-870.

Gillicuddy AM, Kelly M, Crean AM, Sahm LJ. The knowledge, attitudes and beliefs of patients and their healthcare professionals around oral dosage form modification: A systematic review of the qualitative literature. Res Social Adm Pharm. 2017;13(4):717-726.

Guzmán DC, García EH, Olguín HJ, Jiménez FT. Medicamentos empleados em dosis pediátricas unitarias. Acta Pediatr Mex. 2012;33(1):44-47.

International Conference on Harmonization. ICH. Validation of analytical procedures: text and methodology Q2 R1. Geneva: International Conference on Harmonization; 2005. [cited 2017 April 10] Available from: http://www.ich.org/ fileadmin/Public_Web_Site/ICH_Products/Guidelines/ Quality/Q2_R1/Step4/Q2_R1__Guideline.pdf

Jones D. Pharmaceutics: dosage form and design. London: Pharmaceutical Press; 2008. p.5.

Kumar RS, Nathan PS, Nallasivan PK, Solomon WDS, Venkatnarayanan R. A validated reversed phase HPLCmethod for the determination of aceclofenac and tizanidine in tablets. JPRHC. 2010;2(1):84-94.

Lwin EMP, Ellis D, Song Y, Turner S, Williams D, Garg S. Evaluation of the physical, chemical and microbiological stability of compounded carbimazole suspension. Res Social Adm Pharm. 2016a;12(5):e39-e40.

Lwin EMP, Zen WC, Ellis D, Song Y, Turner S, Williams D, et al. Evaluation of the physical, chemical and microbiological stability of compounded minoxidil suspension. Res Social Adm Pharm. 2016b;12(5):e39.

Nalluri BN, Sushmitha K, Sunandana B, Badu DP. Development and validation of RP-HPLC-PDA method for simultaneous estimation of baclofen and tizanidine in bulk and dosage forms. J Appl Pharm Sci. 2012;2(7):111-116.

Narajji C, Patel HR, Karvekar MD, Babu S. Simultaneous Estimation of Aceclofenac, Paracetamol and Tizanidine in Their Combined Dosage Forms by Spectrophotometric and RP- HPLC Method. J Anal Bioanal Techniques. 2011;2(4):2-4. 
Evaluation of physicochemical and microbiological stability of liquid preparation from tizanidine hydrochloride tablets - a Hospital concern

Nikkhah A, Mohammadi M, Ashrafi MR, Zamani GH. The efficacy and safety of tizanidine in treating spasticity in children with cerebral palsy. Iran J Child Neurol. 2011;5(3):19-22.

Palazon GR, Benavente VA, Arroyo RO. Protocol for tizanidine use in infantile cerebral palsy. A Pediatr (Barc). 2008;68(5):511-515.

Pelczar Jr MJ, Chan ECS, Krieg NR. Microbiologia: conceitos e aplicações. 2th ed. São Paulo: Makron Books do Brasil; 1997. p.147.

Qi ML, Wang P, Wang L. Validated liquid chromatography method for assay of tizanidine in drug substance and formulated product. Anal Chim Acta. 2002;478:171-177.

Rosa AM, Gerlin MCG, Alcântara IC, Sversut RA, Cardoso TFM, Rodrigues PO, et al. Desenvolvimento e estudo de estabilidade de formulações extemporâneas de uso oral a partir de comprimidos comerciais contendo espironolactona. Rev Ciênc Farm Básica Apl. 2014;35(3):385-392.
Santos L, Heineck L. Extemporaneous Oral Preparations. An Alternative forHospitalized Children. Lat Am J Pharm. 2011;30(5):996-1000.

Sweetman SC, editor. Martindale: the complete drug reference. 37th ed. London:Pharmaceutical Press; 2011. p. 2062-2063.

The United States Pharmacopeia. 38 ed. Rockville: The United States Pharmacopoeial Convention; 2015.

Wagstaff AJ, Bryson HM. Tizanidine: A review of its pharmacology, clinical efficacy and tolerability in the management of spasticity associated with cerebral and spinal disorders. Drugs. 1997;53(3):435-452.

Received for publication on $24^{\text {th }}$ October 2018 Accepted for publication on $03^{\text {rd }}$ June 2019 